\title{
The use of different alumina fillers for improvement of the mechanical properties of hybrid PMMA composites
}

\author{
Faisal Ali Alzarrug a, Marija M. Dimitrijević ${ }^{b, *}$, Radmila M. Jančić Heinemann ${ }^{\text {a }}$, Vesna Radojević ${ }^{a}$, \\ Dušica B. Stojanović ${ }^{\mathrm{a}}$, Petar S. Uskoković ${ }^{\mathrm{a}}$, Radoslav Aleksić ${ }^{\mathrm{a}, 1}$ \\ a University of Belgrade, Faculty of Technology and Metallurgy, Karnegijeva 4, 11000 Belgrade, Serbia \\ b University of Belgrade, Innovation Center of the Faculty of Technology and Metallurgy, Karnegijeva 4, 11000 Belgrade, Serbia
}

\section{A R T I C L E I N F O}

Article history:

Received 27 May 2015

Received in revised form 10 July 2015

Accepted 12 July 2015

Available online 17 July 2015

\section{Keywords:}

Electrospinning

Bimodal distribution

Hybrid composite

Nanoindentation

Dynamic mechanical analysis

\begin{abstract}
A B S T R A C T
Alumina fillers having different morphologies were used for reinforcement of PMMA-based composite materials. The employed fillers had the same chemical composition but morphologically were spherical nanoparticles, whiskers and an electrospun product that was composed of micro-sized mostly spherical particles and nanofibers. The electrospun product was obtained from aluminum chloride hydroxide/PVA/water solution. All fillers were added without surface treatment and mechanical characteristics of obtained composites were determined using dynamic mechanical analysis (DMA) and nanoindentation. From the nanoindentation results, the reduced elastic modulus for the obtained specimens using 3 wt.\% of electrospun product was $134 \%$ of the one obtained with the polymer alone and the hardness was improved to $157.8 \%$ compared to the polymer without any additive. DMA shows that the storage modulus at room temperature was twice that of the polymer alone.
\end{abstract}

(C) 2015 Elsevier Ltd. All rights reserved.

\section{Introduction}

Poly(methyl methacrylate) (PMMA) is a widely used polymer in cases when the transparency is of utmost importance. PMMA has a favorable biocompatibility and has been used as a restorative material in dentistry and medicine [1]. Reinforced polymer composites have been used for nearly 50 years in restorative components utilized in medicine and dentistry $[2,3]$. The use of this material has recently increased as a result of consumer demands for esthetic restorations, coupled with the public concern of mercury-containing dental amalgam [4]. Composites are now used in over $95 \%$ of all anterior direct restoration teeth and in $50 \%$ of all posterior direct restoration teeth [5]. In medicine, fiberreinforced composites have been used in orthopedics as implants, and load bearing surfaces [6]. In addition, hydroxyapatite composite implant materials have become a promising alternative to acrylic cement in stabilizing fractures and cancellous screw fixation in elderly and osteoporotic patients $[7,8]$. The first use of poly(methyl methacrylate) as a dental device was for the fabrication of complete denture bases $[9,10]$. Although numerous new alloplastic materials show promise, the versatility and reliability of PMMA cause it to remain a popular and frequently used material [11,12].

\footnotetext{
* Corresponding author.

E-mail addresses: faisalalialzarrug@yahoo.com (F.A. Alzarrug), mdimitrijevic@tmf.bg.ac.rs (M.M. Dimitrijević), radica@tmf.bg.ac.rs (R.M. Jančić Heinemann), vesnar@tmf.bg.ac.rs (V. Radojević), duca@tmf.bg.ac.rs (D.B. Stojanović), puskokovic@tmf.bg.ac.rs (P.S. Uskoković).

${ }^{1}$ Deceased.
}

The use of PMMA-based composites is based on the need to achieve favorable mechanical properties with appropriate polymerreinforcement bonding, and benefit from the biocompatibility of PMMA. The even distribution of composite reinforcement particle plays a pivotal role in the durability of a material during long-time service. This is the situation where the properties of the composite are important and when the even distribution of the reinforcement plays a vital role for enabling the material to be used safely and for a long time. The de-agglomeration and distribution of particulate reinforcements in the matrix can be achieved using several techniques of which ultrasonication of the reinforcing particles in the monomer is one of the most efficient techniques for the fabrication of composites with the desired mechanical properties [13].

Electrospinning is a process that enables the production of fine fibrous ceramic structures enabling particles having to obtain shapes with a good capacity for reinforcement to be obtained [14]. Alumina fibers are among the fibers that are easily produced using electrospinning and there are several reported chemical fabrication routes [15,16]. The fibers can be easily produced from precursor chemicals and then transformed into oxides by heat treatment in air [17]. The obtained fibers have promising potentials for use as reinforcements in composite materials. The process can be controlled using different process parameters, such as mass flow of the precursor, the voltage of electric field, chemical composition of the precursor and the distance between the syringe and the collector. By varying the mentioned parameters, the shape and dimensions of the fibers could be adjusted. The products mostly have a fibrous structure, but sometimes it is possible to obtain different shapes 
of the precursor. Appearance of the fiber shapes could be analyzed using image analysis techniques with precise measurement scales [18]. Usually, this technique is coupled with scanning electron microscopy in order to capture the real morphology of the fabricated materials [19].

Elastic modulus and hardness at ambient temperature and under heating cycles are essential for composite characterization. Nanoindentation is a technique that enables the determination of elastic modulus and hardness of a material on submicron scales. In the case of a composite material having nanoparticles as reinforcement, it is essential to elucidate the uniformity of mechanical properties that could be compromised due to uneven particle distribution or weak particlematrix bonding. Dynamic mechanical analysis (DMA) is a sensitive technique that measures the thermo-mechanical response of materials with respect to temperature and the frequency of the applied sinusoidal stress. This analysis enables the determination of the storage modulus $\left(E^{\prime}\right)$, loss modulus $\left(E^{\prime \prime}\right)$, damping factor $(\tan \delta)$ and the ratio between loss modulus ( $\left.E^{\prime \prime}\right)$ and storage modulus ( $\left.E^{\prime}\right)$ (Cole-Cole plot). DMA also enables the determination of the glass transition temperature $\left(T_{\mathrm{g}}\right)$ of the composite and an evaluation of the contact between the reinforcement and the matrix. A comparison of the results of these methods gives the possibility to study the mechanical behavior of the composite and to evaluate the influence of the shape and quantity of the reinforcement.

The goal of this research was to examine the feasibility of using electrospun alumina fillers as reinforcement for PMMA-based hybrid composite materials. The influence of the size and shape of electrospun alumina fillers on the mechanical properties of the hybrid composites was studied and compared with those of the two types of composites prepared using industrial alumina fillers: alumina spherical particles and alumina whiskers. All fillers were added without surface modification, which makes the process very simple and lowers the cost of the processing of the materials.

\section{Materials and methods}

\subsection{Materials}

Aluminum chloride hydroxide (Locron L) was purchased from the Clariant Company in the crystallized state of $\mathrm{Al}_{2} \mathrm{Cl}(\mathrm{OH})_{5} \cdot 2.5 \cdot \mathrm{H}_{2} \mathrm{O}$. The PVA used had a weight average molecular weight $\left(\bar{M}_{\mathrm{w}}\right)$ of $\approx 130,000 \mathrm{~g} \mathrm{~mol}^{-1}$ and degree of hydrolysis of $86.7-88.7 \mathrm{~mol} \%$, and was purchased under the label Mowiol 18-88 (Aldrich). Mecaprex KM, PRESI (Grenoble, France) autopolymerizing acrylic resins consisted of KM powder (PMMA powder containing dibenzoyl peroxide (DBPO) initiator) and of KM liquid monomer (methyl methacrylate monomer MMA with N,N-dimethyl-p-toluidine as an activator). The spherical aluminum oxide nanoparticles and alumina whiskers were commercially available from Aldrich.

\subsection{Methods}

\subsubsection{Fast preparation of electrospun alumina fibers}

For the preparation of alumina ceramic fibers, a fast electrospinning procedure was used. The precursor was based on alumina chloride hydroxide and poly(vinyl alcohol), which served to enable the good spinnability of the solution and to ease the handling of the precursor fibers. The procedure for precursor preparation was selected so as to enable the preparation of mixtures having a desired ratio of aluminum oxide to the polymer in the solution. A $5 \mathrm{wt}$.\% aqueous solution of polymer was used and the aluminum chloride hydroxide was added into the solution. The desired mass ratio of aluminum chloride hydroxide to polymer in the mixture was 5 to 1 . The solution was then stirred using a laboratory mixer for $1 \mathrm{~h}$ at $30^{\circ} \mathrm{C}$ to obtain a homogeneous solution. The resulting solution contained air bubbles that disappeared after $24 \mathrm{~h}$.

An Electrospinner $\mathrm{CH}-01$ electrospinning apparatus (Linari Engineering, Italy) was used for the fiber preparation. A high-voltage supply
(SPELMANN PCM50P120, USA) capable of producing $30 \mathrm{kV}$ was used in the experiments. The polymer solutions were supplied to the nozzles using R100E type syringe pumps (Razel Scientific Instruments, USA). The solution was placed into the $20 \mathrm{ml}$ plastic syringe having a needle of $0.8 \mathrm{~mm}$ orifice. The voltage used to have a stable process was of $28 \mathrm{kV}$ and the mass flow rate was $20 \mathrm{ml} / \mathrm{h}$. The process was conducted in air at an ambient temperature of $21^{\circ} \mathrm{C}$. The distance between the needle and the collector was fixed at $15 \mathrm{~cm}$. Aluminum foil was placed at the bottom of the installation. After completion of the electrospinning, the electrospun fibers were calcined at $1100^{\circ} \mathrm{C}$ for $1 \mathrm{~h}$ in order to obtain electrospun alumina fillers [20]. The XRD pattern of the sample calcined at $1100{ }^{\circ} \mathrm{C}$ indicated that the $\alpha$-alumina phase was formed (Fig. 1a). Two industrially available fillers were selected in order to compare the prepared electrospun alumina fillers. These were spherical aluminum oxide nanoparticles, declared to have diameters of less than $50 \mathrm{~nm}$, and alumina whiskers characterized with diameters of 2-4 nm and lengths of 200-400 nm. Thus very different alumina fillers were examined, spherical alumina nanoparticles, with the length to diameter ratio of 1 , and alumina whiskers having a length to diameter ratio of approximately 100 .

\subsubsection{Preparation of hybrid PMMA composites}

Alumina spherical nanoparticles, alumina whiskers or electrospun alumina fillers were added to KM liquid. The mixture was sonicated for $60 \mathrm{~min}$ and $\mathrm{KM}$ powder was dispersed in the mixture. The mixing was performed by hand for 2 min and the mixture was poured out in a cast form having dimensions suitable for DMA and nanoindentation testing. The form was covered using a glass cover to ensure that the surface of the specimen remained smooth. A PMMA/MMA mass ratio of 0.75 was used as this ratio enables minimization of shrinkage as suggested by the manufacturer (PRESI) and as previously reported in the literature [21]. The polymerization of the monomer was realized at a temperature of $25^{\circ} \mathrm{C}$. The manufacturer's suggestion states that the polymerization is considered to be completed in $20 \mathrm{~min}$ at a temperature between 20 and $23^{\circ} \mathrm{C}$. The obtained composites were then exposed to a temperature of $37^{\circ} \mathrm{C}$ for 30 days before they were mechanically tested in order to obtain the stable composition of the polymer matrix of the composite [22]. The compositions of the composites PMMA/alumina whiskers and PMMA/alumina spherical nanoparticles prepared for analysis in this study are summarized in Table 1 . The samples prepared using the alumina spherical nanoparticles as the filler were denoted P1, P3 and P5 for the addition of $1 \mathrm{wt} . \%, 3 \mathrm{wt} . \%$ and $5 \mathrm{wt} . \%$ of the filler, respectively. The samples using alumina whiskers as fillers were denoted $\mathrm{W} 1, \mathrm{~W} 3$ and $\mathrm{W} 5$ for the addition of $1 \mathrm{wt} . \%, 3 \mathrm{wt} . \%$ and $5 \mathrm{wt} . \%$ alumina whiskers, respectively. The samples using the electrospun bimodal alumina product having the same contents of fillers as those having industrially produced alumina fillers are annotated as F1, F3 and F5 for the respective contents of $1 \mathrm{wt} . \%, 3 \mathrm{wt} . \%$ and $5 \mathrm{wt} . \%$ alumina electrospun fillers, respectively.

\subsection{Characterization}

\subsubsection{DMA analysis}

Dynamic mechanical analysis was used to examine the performance of the PMMA matrix composite reinforced with alumina spherical nanoparticles, alumina whiskers and electrospun alumina fillers in order to analyze the influence of the size and shape of the alumina filler on the behavior of the fabricated composites. The storage modulus revealed the ability of the composites to store elastic energy associated with recoverable elastic deformation. Together with tangent delta, the storage modulus describes the behavior of the composite under stress in a defined temperature range. The effect of the structural changes of neat polymer matrix was also confirmed by a Cole-Cole plot where the loss modulus data are plotted as a function of the storage modulus. Dynamic mechanical analysis was performed (DMA Q800, TA Instruments) under a nitrogen atmosphere and the single cantilever mode. Storage modulus 


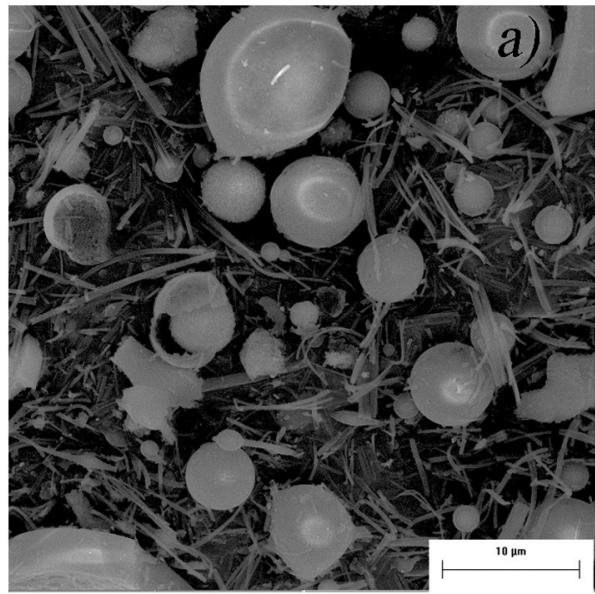

b)

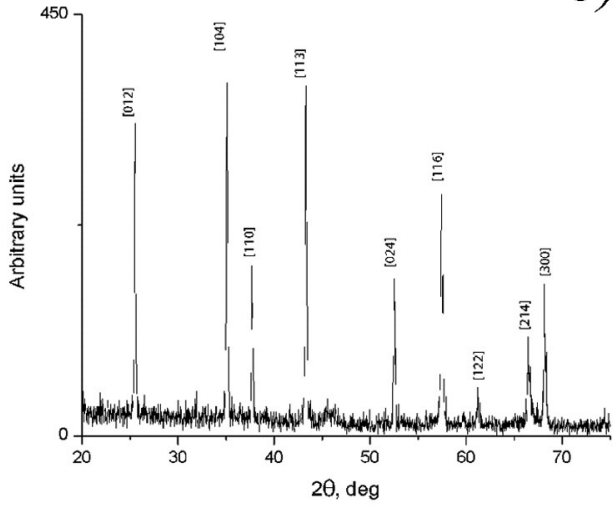

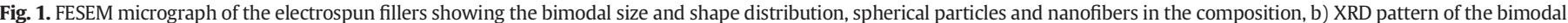
alumina product calcinated at $1100{ }^{\circ} \mathrm{C}$.

$\left(E^{\prime}\right)$, loss factor $(\tan \delta)$ and the Cole-Cole plot were calculated for rectangular specimens of size $35 \mathrm{~mm} \times 13 \mathrm{~mm} \times 3 \mathrm{~mm}$ at frequency $\omega=1 \mathrm{~Hz}$. Temperature range was changed from room temperature to $150{ }^{\circ} \mathrm{C}$ at a heating rate of $3{ }^{\circ} \mathrm{C} / \mathrm{min}$.

\subsubsection{Nanoindentation}

The nanoindentation test was performed using a Hysitron TI 950 TriboIndenter equipped with in situ SPM imaging (Hysitron, MN). The Berkovich indenter had an average radius of curvature of about $100 \mathrm{~nm}$. The tests were performed in force-controlled feedback mode. The indentation maximum load was set at $4 \mathrm{mN}$ for each tested sample. The loading and unloading times as well as the hold time at the peak force were all set to $25 \mathrm{~s}$. For each loading/hold/unloading cycle, the applied load value was plotted with respect to the corresponding position of the indenter. The resulting load/displacement curve provides data specific to the mechanical nature of the material under examination. All the results were obtained using the Oliver \& Pharr method [19], employing a supposed sample for the reduced elastic modulus calculation. Established models were used to calculate the values of the quantitative hardness $(H)$ and reduced elastic modulus $(E)$ for such data. The specimens were polished using alumina paste having abrasive grains up to $0.02 \mu \mathrm{m}$ until the average roughness (RA) of samples containing alumina particles was $38.89 \mathrm{~nm}$, with alumina whiskers was $28.09 \mathrm{~nm}$ and with electrospun alumina fillers was $25.24 \mathrm{~nm}$ (please see Graphical abstract). The specimens were about having dimensions $3 \times 3 \times 2 \mathrm{~mm}$ and were placed on the specimen holder in the nanoindenter. On each tested sample, nine indentations were made at random positions ensuring that the distance between indents was at least $7.5 \mu \mathrm{m}$.

Table 1

The compositions of composite specimens prepared using the PMMA as the matrix and different fillers.

\begin{tabular}{llll}
\hline Sample & Quantity of fillers $(\mathrm{g})$ & Mass MA + initiator $(\mathrm{g})$ & Mass MMA $(\mathrm{g})$ \\
\hline PMMA & - & 2.290 & 1.710 \\
P1 & 0.045 & 2.540 & 1.910 \\
P3 & 0.135 & 2.540 & 1.870 \\
P5 & 0.225 & 2.440 & 1.830 \\
W1 & 0.045 & 2.540 & 1.910 \\
W3 & 0.135 & 2.540 & 1.870 \\
W5 & 0.225 & 2.440 & 1.830 \\
F1 & 0.045 & 2.540 & 1.910 \\
F2 & 0.135 & 2.540 & 1.870 \\
F5 & 0.225 & 2.440 & 1.830
\end{tabular}

\subsubsection{XRD analysis}

Crystallographic phases formed in the heat treated fibers were determined by X-ray diffraction analysis. The XRD patterns were recorded on an Ital Structure APD2000 X-ray diffractometer in the BraggBrentano geometry using $\mathrm{CuK} \alpha$ radiation $(\lambda=1.5418 \AA$ ) and the step-scan mode (range: $20-75^{\circ} 2 \theta$, step-time: 0.50 s, step-width: $0.02^{\circ}$ ). The corundum structure of the alumina fillers was confirmed by comparison of the XRD data to the standard card 93096-ICSD.

\subsubsection{Analysis of the morphology of the specimens}

The morphology of the electrospun alumina fillers and the morphology of the samples were examined using a field emission scanning electron microscope (FESEM), MIRA3 TESCAN, operated at $20 \mathrm{kV}$. The electrospun alumina products were analyzed after heat treatment and prior to use as reinforcements. The bimodal size and shape distribution of the electrospun alumina fillers were measured using Image-Pro Plus 4.2 analysis software (Media Cybernetics) by manual measurements of the particle and fiber diameters.

\section{Results and discussion}

\subsection{Characterization of the morphology of the electrospun alumina fibers}

The product of electrospinning was characterized after heat treatment so the product that was used as reinforcement could be wellknown from the morphological point of view. The field emission scanning electron microscope was used for morphological characterization of the product as it enables better visibility of fine fibers produced using this method (Fig. 1a). These images were used to evaluate the content of spherical micron sized particles and nanofibers in the composition. This was realized using the image analysis technique as in the images these features could be separated. The volume fraction of the particles and fibers was evaluated according to the surface occupied in the image. The content of fibers in the product was $45 \mathrm{vol} . \%$ and the content of spherical micron sized particles was 55 vol.\%. The particles and fibers were also characterized using the image analysis technique and the mean diameter of the particles in the electrospun product was $3.5 \mu \mathrm{m}$ and that of electrospun nanofibers was about $310 \mathrm{~nm}$. The corresponding histograms of the distribution of the diameters of the particles and nanofiber are given in Fig. 2.

Ahmed Ben Hasan et al. [21] characterized the industrially available alumina spherical nanoparticles and alumina whiskers prior to utilization and the average mean diameter of agglomerates were found to be $87 \mu \mathrm{m}$ and $1.1 \mu \mathrm{m}$ for alumina spherical nanoparticles and alumina whiskers, respectively. 

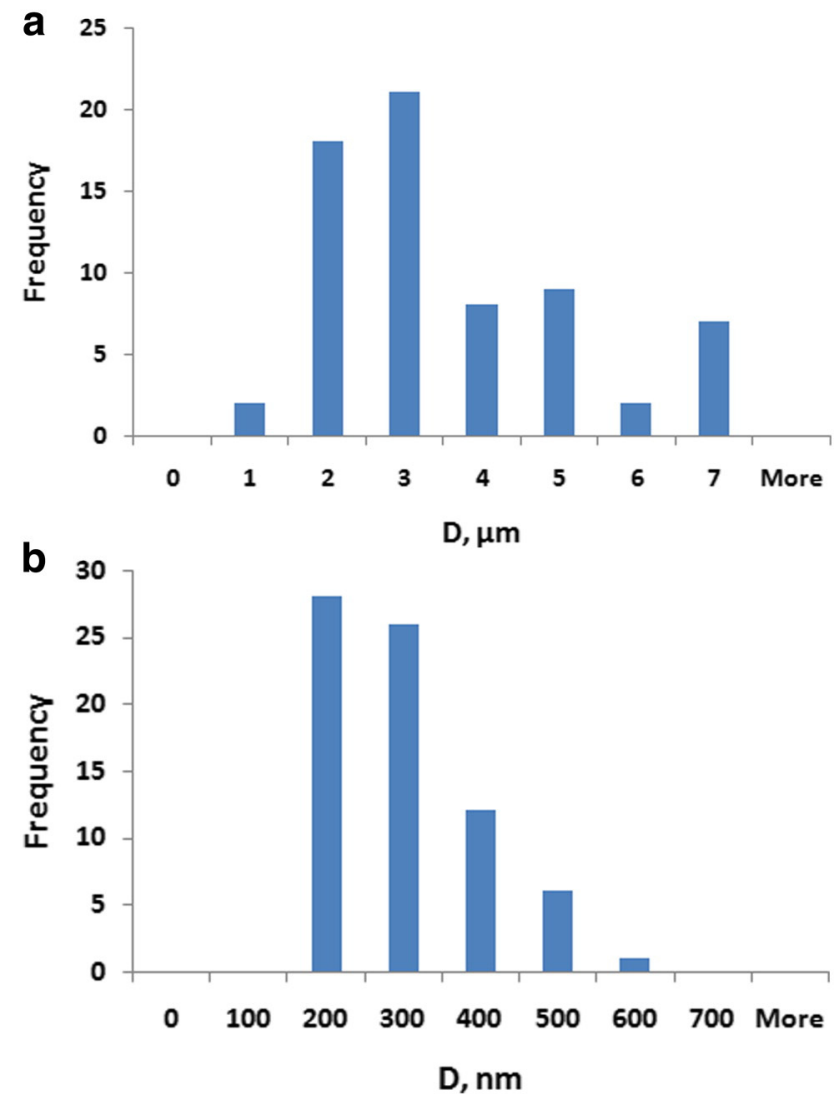

Fig. 2. Histograms of particles and nanofibers obtained by electrospinning of an aqueous PVA solution of aluminum chloride hydroxide after heat treatment at $1100^{\circ} \mathrm{C}$

The micrographs of composites having PMMA and different contents of bimodal alumina fillers are presented in Fig. 3.

Hybrid composite containing $1 \mathrm{wt} . \%$ and 3 wt.\% electrospun fillers had a good distribution of fibers in the volume of the matrix, whereas the specimen containing $5 \mathrm{wt} . \%$ showed some tendencies of agglomeration of the fibrous and particulate filler and this resulted in a less homogeneous distribution. In the image of the cross section of the composite having $5 \mathrm{wt} . \%$ of the electrospun filler, the product established looser contact to the matrix and this could explain the deterioration of the mechanical properties compared to the composites having 3 wt.\% of electrospun alumina fillers.

\subsection{Characterization using DMA}

The main goal of the addition of the ceramic fillers into the polymer matrix was improvement of the mechanical properties. The obtained mechanical properties of composites having electrospun alumina fillers were compared to the composites reinforced using the commercial spherical nanoparticles and commercial alumina whiskers. Comparison of the influence of the filler size and shape on the mechanical properties of the composites showed that the elongated form of the filler, i.e., the whiskers, was favorable to the improvement of the mechanical properties. Comparison of the mechanical properties of the composites showed that the improvement was the most obvious when the electrospun alumina fillers were used as the reinforcement.

The composites having $1 \mathrm{wt} . \%, 3 \mathrm{wt} . \%$ and $5 \mathrm{wt} . \%$ of bimodal alumina fillers as reinforcement were compared to the polymer without reinforcement using dynamic mechanical testing. The comparison of storage modulus at a temperature of $30{ }^{\circ} \mathrm{C}$ showed that any addition of bimodal alumina fillers increased the modulus; thus, the addition of $1 \mathrm{wt} . \%$ of electrospun fillers increased the storage modulus by about $16 \%$ and the addition of $5 \mathrm{wt} . \%$ of electrospun bimodal fillers increased
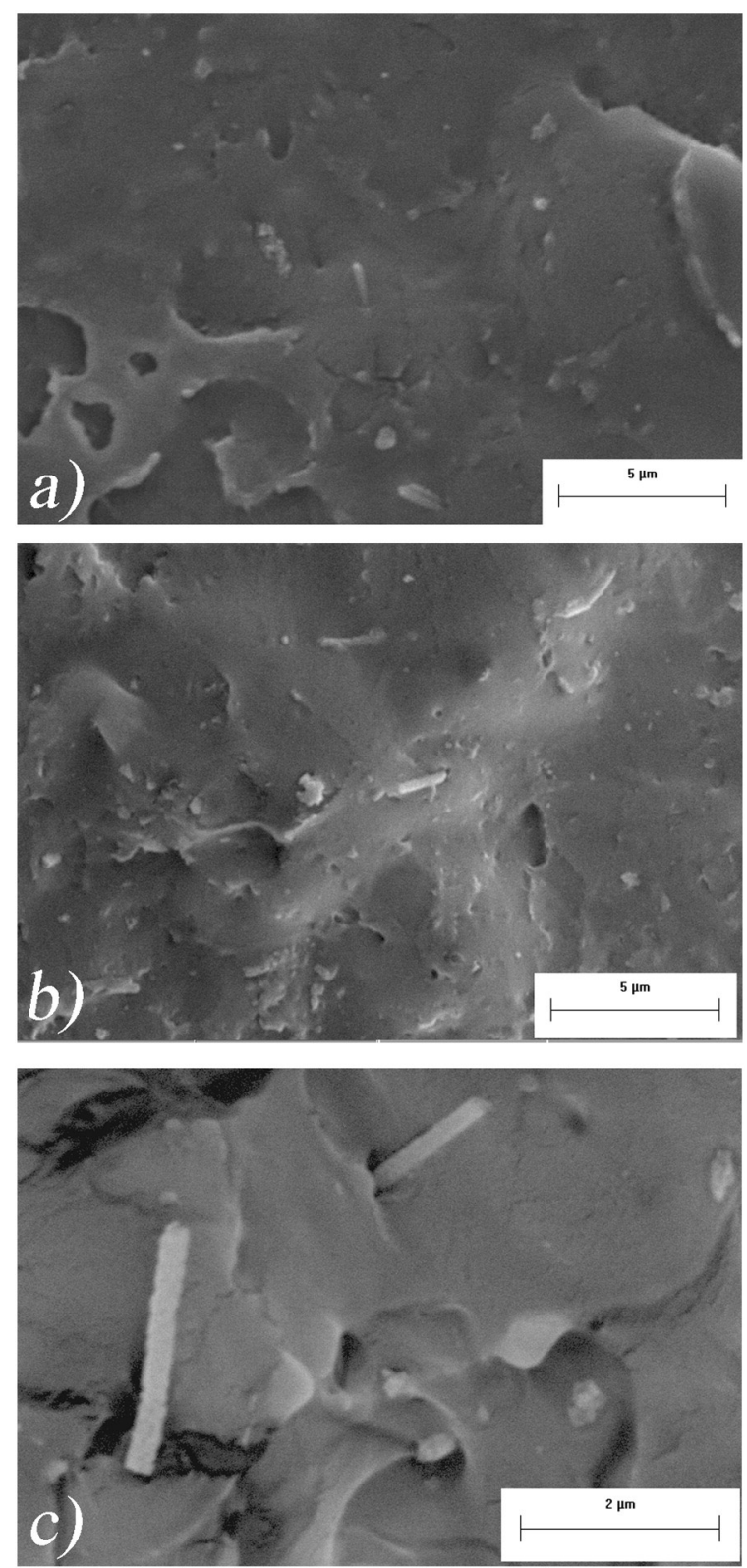

Fig. 3. The SEM micrographs of hybrid composite of PMMA and a) 1 wt.\% of bimodal alumina filler, b) $3 \mathrm{wt} . \%$ of bimodal alumina filler and c) $5 \mathrm{wt}$.\% of bimodal alumina filler.

the storage modulus by $63 \%$. The composite having $3 \mathrm{wt} . \%$ of alumina fillers increased the value of the storage modulus by about $100 \%$ and the obtained value was almost the double that of the polymer without any reinforcement. Thus the samples having $3 \mathrm{wt} . \%$ of bimodal alumina fillers and better values of modulus measured by DMA than the samples containing $5 \mathrm{wt}$ \% of electrospun fillers. The properties of the composites obtained from DMA testing are presented in Table 2, Figs. 4-5 and in a previous work [21].

The $T_{\mathrm{g}}$ values were determined from the DMA measurement and the values were compared to the PMMA without the addition of

Table 2

Properties of composites obtained from DMA testing.

\begin{tabular}{lcccccc}
\hline Sample & PMMA & \multicolumn{1}{l}{ F1 } & F3 & F5 & P3 & W3 \\
\hline$E^{\prime},\left(30{ }^{\circ} \mathrm{C}\right), \mathrm{MPa}$ & 1186 & 1379 & 2371 & 1937 & 1288 & 1932 \\
$\mathrm{~T}_{\mathrm{g}}\left({ }^{\circ} \mathrm{C}\right)$ & 95.6 & 95.6 & 100.4 & 101.9 & 93.9 & 98.5 \\
Tan $\delta$ & 1.45 & 1.22 & 1.16 & 1.17 & 1.00 & 1.17
\end{tabular}




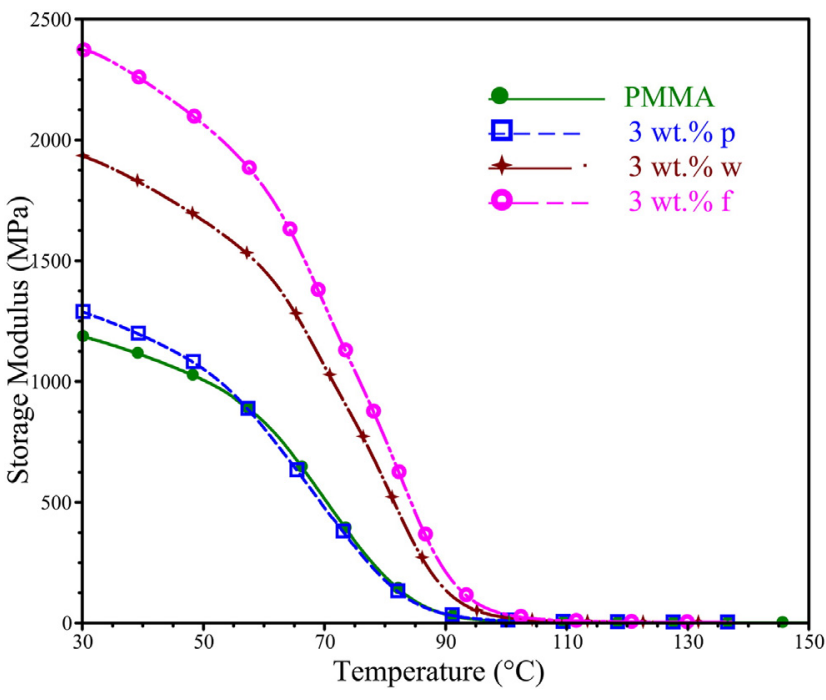

Fig. 4. Comparison of storage modulus obtained from DMA analysis of composites of a PMMA matrix with alumina fillers of different shapes.

reinforcement. The $T_{\mathrm{g}}$ of PMMA was $95.6^{\circ} \mathrm{C}$ and the $T_{\mathrm{g}}$ for the composite with spherical alumina particles was $93.9^{\circ} \mathrm{C}$. The composite obtained by the addition of $3 \mathrm{wt} . \%$ of whiskers had a $T_{\mathrm{g}}$ at $98.5^{\circ} \mathrm{C}$. The highest value of the $T_{\mathrm{g}}$ was observed for the composite obtained using electrospun alumina fillers. A comparison of the $T_{\mathrm{g}}$ value of the pure polymer to that of the composite containing $1 \mathrm{wt} . \%$ electrospun alumina fillers showed that the values were approximately the same. Addition of $3 \mathrm{wt} . \%$ of electrospun alumina fillers increases the $T_{\mathrm{g}}$ value by about $4.8^{\circ} \mathrm{C}$ and the addition of $5 \mathrm{wt} . \%$ fillers increased the value by more than $6{ }^{\circ} \mathrm{C}$. The values of the $T_{\mathrm{g}}$ increased with the addition of electrospun alumina fillers, indicating that the thermal stability of the composites increased with the addition of the reinforcement.

In this study, all reinforcements had the same chemical composition, but the shapes of the fillers were different. A comparison of the composites having fillers of the same chemical composition and quantity of reinforcement but having different shapes is presented in Fig. 4. It could be seen that the behavior of the composite having electrospun alumina fillers has the highest value of all composites at all examined temperatures. The improvement in values of storage modulus for the addition of spherical alumina particles as a filler is not very important and at

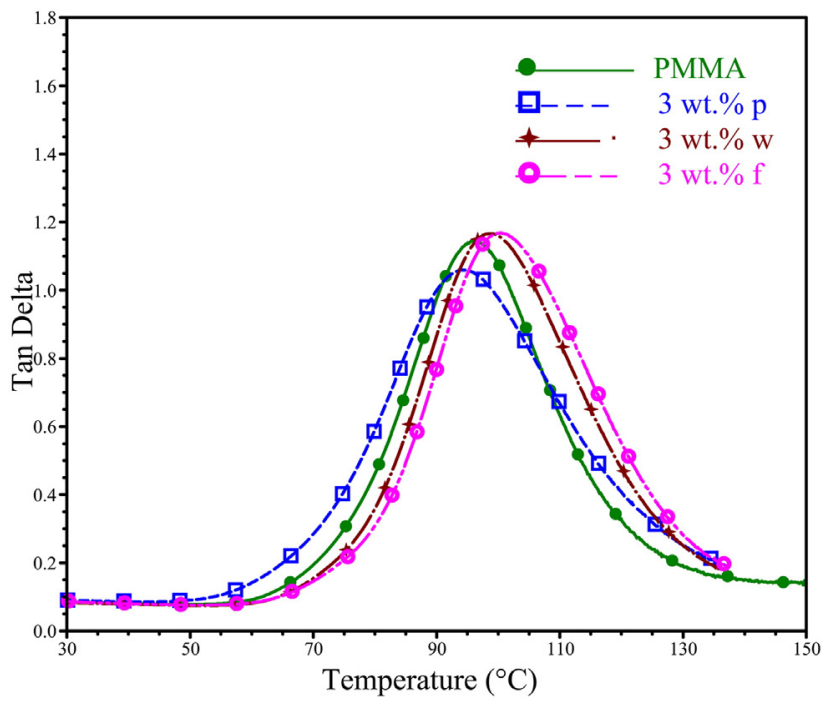

Fig. 5. Values of $\tan \delta$ measured at temperatures from $30^{\circ} \mathrm{C}$ to $150^{\circ} \mathrm{C}$ for the PMMA matrix and the matrix containing alumina fillers having different shapes. temperatures above $110^{\circ} \mathrm{C}$, the values of storage modulus are slightly lower than those for the polymer without any added filler. The improvements observed with the addition of whiskers were present over the whole studied temperature range. The improvements in storage modulus values were most visible for the composites containing electrospun alumina fillers for the temperature range from $30^{\circ} \mathrm{C}$ up to $150{ }^{\circ} \mathrm{C}$. The increase in the values of the storage modulus compared to that of the pure polymer matrix was $9 \%$ for the spherical alumina particles, $63 \%$ for the alumina whiskers and $100 \%$ for the electrospun alumina fillers.

Comparison of results obtained from the DMA testing of the specimens having the same quantity of spherical particles and electrospun fillers added showed that the maximum value of $\tan \delta$ was higher for the specimen with the electrospun alumina filler than the one containing spherical nanoparticles (Fig. 5). The decreasing height of the $\tan \delta$ peak is due to the reduced fraction of the polymer matrix, and the better behavior is attributed to the fact that more polymer chains are restricted in the polymer/nanoparticles interphase. The bonding established between the spherical nanoparticles and the matrix was better compared to that obtained using the electrospun product in the same matrix. This finding could be explained by the fact that the electrospun product was heat treated at $1100{ }^{\circ} \mathrm{C}$ and this heat treatment destroyed the hydroxyl groups at the surface of the filler. On the other hand, the crystals in the structure of the electrospun alumina fillers (Fig. 1b) were very well defined and the product obtained has a pure corundum structure, and addition of such fillers resulted in a product having higher values of the $T_{\mathrm{g}}$.

In comparison with the pure PMMA matrix, the composites obtained in this study all had hybrid structures, probably due to the presence of dispersed and agglomerated spherical alumina particles and alumina whiskers that were not modified. This can be seen in Fig. 6 showing the Cole-Cole plot [22] of the polymer and hybrid composites with the same amount of different fillers. The highest level of hybrid behavior had the one prepared using electrospun bimodal alumina fillers as it has two sorts of filler having different sizes and shapes.

\subsection{Characterization using nanoindentation}

Nanoindentation measurements were performed on nine positions for every sample in order to obtain an overview of the possible inhomogeneity of the sample. The mean values of the nine measurements were used for further analysis, Figs. 7 and 8. The data about the reduced modulus of elasticity and hardness of the samples were analyzed, Fig. 9. The relative increases of the values of hardness and modulus obtained using nanoindentation are given in Table 3.

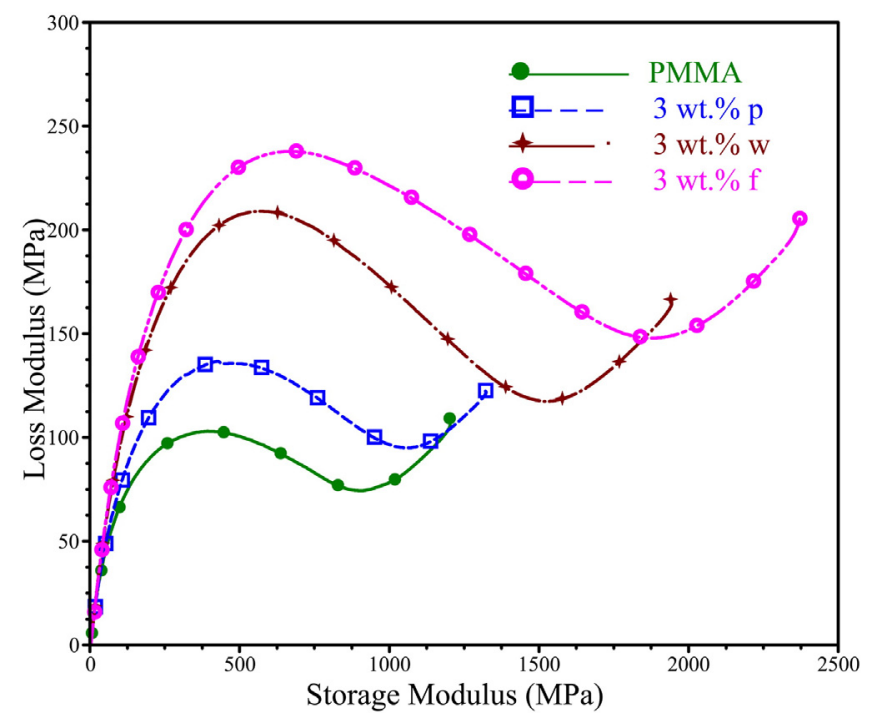

Fig. 6. Cole-Cole plots for hybrid composites. 


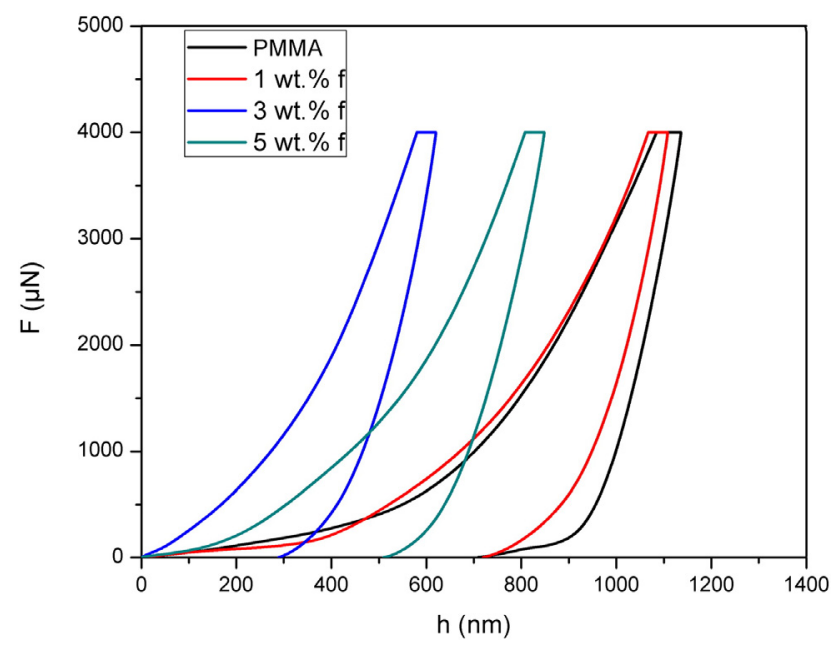

Fig. 7. Nanoindentation curves for the best performing specimens obtained using $1 \mathrm{wt} . \%$, $3 \mathrm{wt} . \%$ and $5 \mathrm{wt} . \%$ of electrospun alumina fillers.

For the addition of $1 \mathrm{wt} . \%$ of alumina fillers, the increases of the reduced modulus of elasticity obtained from the nanoindentation experiments were modest. The addition of $3 \mathrm{wt} . \%$ of the alumina fillers did increase the values of modulus significantly for alumina whiskers and alumina electrospun fillers. The increase in the modulus was most significant for alumina electrospun fillers. The addition of $5 \mathrm{wt} . \%$ of electrospun alumina fillers and alumina whiskers did not additionally improve the values of modulus of elasticity. The improvement was less important in the cases of the addition of alumina spherical particles. This suggests that the morphology of the filler is very important for an improvement in the mechanical properties.

Mean values for reduced elastic modulus and hardness measured using nanoindentation are presented in Fig. 9. The addition of $1 \mathrm{wt} . \%$ of any of the used fillers did not improve the hardness values. The addition of $3 \mathrm{wt} . \%$ of the whiskers and electrospun alumina product resulted in improvements in the reduced elastic modulus and hardness, whereas the addition of the spherical nanoparticles did not improve significantly the hardness of the obtained composite. The improvement of elastic modulus for addition of electrospun product was $134 \%$ compared to the polymer without any additions. The addition of $5 \mathrm{wt} . \%$ electrospun

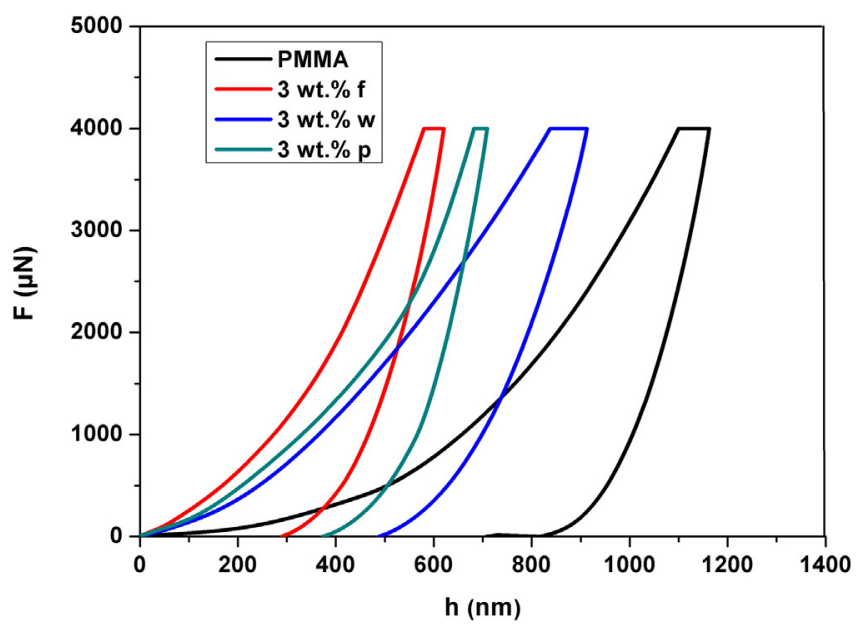

Fig. 8. Nanoindentation curves for the best performing specimens obtained using $3 \mathrm{wt} . \%$ of fillers having a different morphology showing that the best modulus was observed in specimens having electrospun nanofibers as the filler. The two other fillers having spherical nanoparticles and whiskers had lower values of the reduced modulus of elasticity.
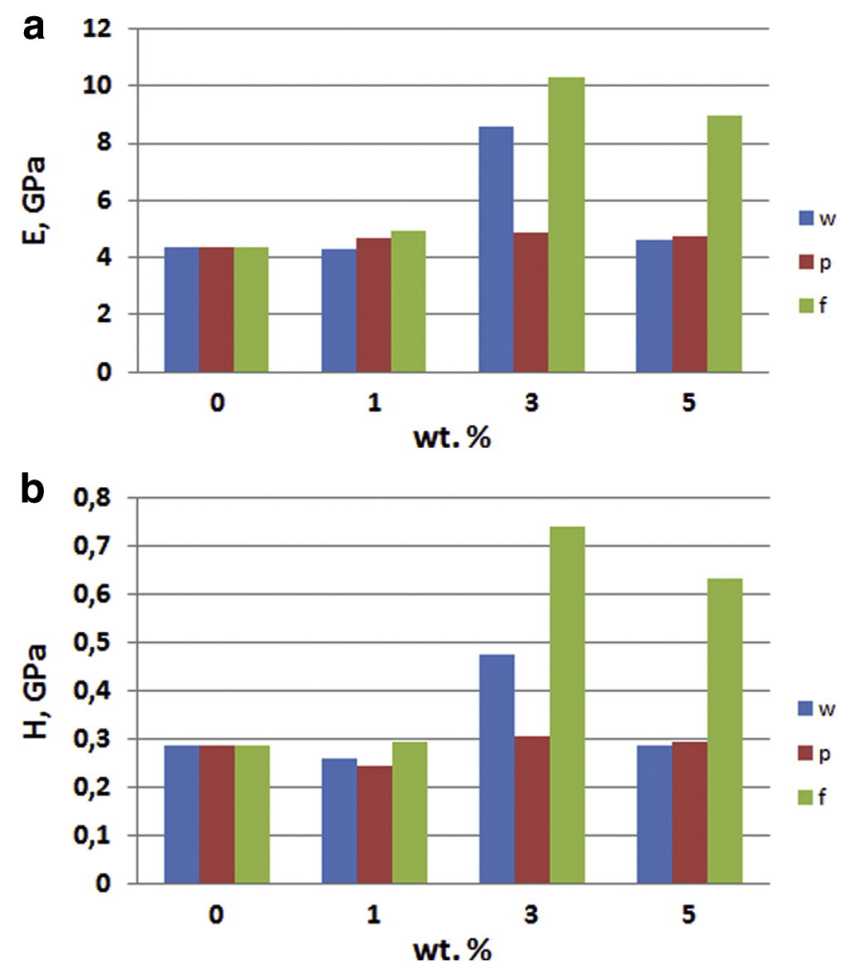

Fig. 9. Mean values of reduced elastic modulus and hardness measured using the nanoindentation technique for specimens containing different fillers.

product did not improve the values of the reduced modulus. Furthermore, the hardness values was significantly improved to $157.8 \%$ on addition of $3 \mathrm{wt} . \%$ electrospun product, while the improvement of the hardness was $120.2 \%$ for the sample containing 5 wt.\% of electrospun product.

\subsection{Comparison of nanoindentation and DMA data for mechanical properties}

Obtained composites were tested using two different methods, giving data that could lead to an interpretation of the observed mechanical properties of the specimens. Comparison of the modulus values obtained by means of nanoindentation with those obtained by means of DMA revealed that the former technique yielded significantly higher values than the latter. This result is mainly attributable to the difference in the applied forces, but the obtained data are in accordance for the modulus values obtained using the two different methods. The best performance observed by both methods exhibited the material having 3 wt.\% of electrospun alumina fillers.

Table 3

Values of reduced modulus and hardness with standard deviation and increase relative to the polymer without fillers.

\begin{tabular}{lclll}
\hline & $\mathrm{E}_{\mathrm{r}}(\mathrm{GPa})$ & $\mathrm{St} \mathrm{dev}$ & $\mathrm{H}(\mathrm{GPa})$ & $\mathrm{St} \mathrm{dev}$ \\
\hline PMMA & 4.39 & 0.378 & 0.287 & 0.090 \\
F1 & 4.95 & 1.096 & 0.292 & 0.117 \\
F3 & 10.28 & 3.073 & 0.741 & 0.456 \\
F5 & 8.94 & 2.575 & 0.633 & 0.347 \\
P1 & 4.70 & 0.665 & 0.242 & 0.0514 \\
P3 & 4.85 & 1.212 & 0.31 & 0.0780 \\
P5 & 4.73 & 0.627 & 0.29 & 0.0425 \\
W1 & 4.27 & 0.493 & 0.26 & 0.0529 \\
W3 & 8.60 & 1.900 & 0.47 & 0.1458 \\
W5 & 4.62 & 0.515 & 0.29 & 0.0784 \\
\hline
\end{tabular}




\section{Conclusion}

Fast electrospinning was used to produce alumina fillers suitable for the preparation of composite materials. The conditions of the filler fabrication resulted in a product having a size and shape distribution that could be characterized as bimodal. Fine fibers having nano dimensions were produced as well as a product characterized by the presence of micron-sized particles. These two fractions were calcinated at $1100{ }^{\circ} \mathrm{C}$ and the obtained bimodal alumina product represented a filler that improved the mechanical properties of the material. The quantity of the added filler was changed and the best mechanical performance was observed for $3 \mathrm{wt}$ \% of added filler. The obtained results were compared to the mechanical properties of composites obtained using commercially available fillers in the form of spherical nano particles and in the form of whiskers. The addition of the whiskers resulted in a product with better mechanical properties than was obtained by the addition of the spherical nanoparticles. The addition of the electrospun alumina product having micron-sized particles and nano-sized fibers gave a composite with the best performance from those studied when $3 \mathrm{wt} . \%$ of this product was added to fabricate the composite.

\section{Acknowledgment}

This research was financially supported by the Ministry of Education, Science and Technological Development of the Republic of Serbia as a part of the project TR34011.

\section{References}

[1] G. Bayraktar, B. Guvener, C. Bural, Y. Uresin, Influence of polymerization method, curing process, and length of time of storage in water on the residual methyl methacrylate content in dental acrylic resins, J. Biomed. Mater. Res. B Appl. Biomater. 76B (2006) 340-345

[2] J. Zhang, J. Liao, A. Mo, Y. Li, J. Li, X. Wang, Characterization and human gingival fibroblasts biocompatibility of hydroxyapatite/PMMA nanocomposites for provisional dental implant restoration, Appl. Surf. Sci. 255 (2008) 328-330.

[3] X. Wang, L. Wang, Q. Su, J. Zheng, Use of unmodified $\mathrm{SiO}_{2}$ as nanofiller to improve mechanical properties of polymer-based nanocomposites, Compos. Sci. Technol. 89 (2013) 52-60.

[4] M.B. Correa, M.A. Peres, K.G. Peres, B.L. Horta, A.D. Barros, F.F. Demarco, Amalgam or composite resin? Factors influencing the choice of restorative material, J. Dent. 40 (2012) 703-710.

[5] M.E. Khalaf, Q.D. Alomari, R. Omar, Factors relating to usage patterns of amalgam and resin composite for posterior restorations - a prospective analysis, J. Dent. 42 (2014) 785-792.
[6] A.M. Ballo, I. Cekic-Nagas, G. Ergun, L. Lassila, A. Palmquist, P. Borchardt, J. Lausmaa, P. Thomsen, P.K. Vallittu, T.O. Närhi, Osseointegration of fiber-reinforced composite implants: histological and ultrastructural observations, Dent. Mater. 30 (2014) 384-395.

[7] J. Pino-Mínguez, A. Jorge-Mora, R. Couceiro-Otero, C. García-Santiago, Study of the viability and adhesion of osteoblast cells to bone cements mixed with hydroxyapatite at different concentrations to use in vertebral augmentation techniques, Rev. Esp. Cir. Ortop. Traumatol. 59 (2015) 122-128 (English Edition).

[8] P.S. Stein, J. Sullivan, J.E. Haubenreich, P.B. Osborne, Composite resin in medicine and dentistry, J. Long-Term Eff. Med. Implants 15 (2005) 641-654.

[9] J.W. Stanford, C.L. Burns, G.C. Paffenbarger, Self-curing resins for repairing dentures: some physical properties, J. Am. Dent. Assoc. 51 (1955) 307-315.

[10] D. Rentería-Zamarrón, D.A. Cortés-Hernández, L. Bretado-Aragón, W. Ortega-Lara, Mechanical properties and apatite-forming ability of PMMA bone cements, Mater. Des. 30 (2009) 3318-3324.

[11] R.Q. Frazer, R.T. Byron, P.B. Osborne, K.P. West, PMMA: an essential material in medicine and dentistry, J. Long-Term Eff. Med. Implants 15 (2005) 629-639.

[12] C. Chen, D. Li, Q. Hu, R. Wang, Properties of polymethyl methacrylate-based nanocomposites: reinforced with ultra-long chitin nanofiber extracted from crab shells, Mater. Des. 56 (2014) 1049-1056.

[13] M. Barathi, A. Santhana Krishna Kumar, N. Rajesh, A novel ultrasonication method in the preparation of zirconium impregnated cellulose for effective fluoride adsorption, Ultrason. Sonochem. 21 (2014) 1090-1099.

[14] C. Peng, P. Liu, J. Hu, T. Hua, Y. Shen, B. Zhao, G. Tang, Preparation of uniaxially aligned mullite ceramic fibers by electrospinning, Colloids Surf. A 457 (2014) 1-7.

[15] A. Mahapatra, B.G. Mishra, G. Hota, Synthesis of ultra-fine $\alpha-\mathrm{Al}_{2} \mathrm{O}_{3}$ fibers via electrospinning method, Ceram. Int. 37 (2011) 2329-2333.

[16] V. Maneeratana, W.M. Sigmund, Continuous hollow alumina gel fibers by direct electrospinning of an alkoxide-based precursor, Chem. Eng. J. 137 (2008) 137-143.

[17] R. Jančić, R. Aleksić, Influence of formation conditions and precursor viscosity on mean fiber diameter formed using the rotating disk method, Mater. Lett. 42 (2000) 350-355.

[18] P. Milanović, M. Dimitrijević, R. Jančić Heinemann, J. Rogan, D.B. Stojanović, A. Kojović, R. Aleksić, Preparation of low cost alumina nanofibers via electrospinning of aluminium chloride hydroxide/poly(vinyl alcohol) solution, Ceram. Int. 39 (2013) 2131-2134.

[19] W.C. Oliver, G.M. Pharr, An improved technique for determining hardness and elastic modulus using load and displacement sensing indentation experiments, J. Mater. Res. 7 (1992) 1564-1583.

[20] M. Hussain, A. Nakahira, K. Niihara, Mechanical property improvement of carbon fiber reinforced epoxy composite by $\mathrm{Al}_{2} \mathrm{O}_{3}$ filler dispersion, Mater. Lett. 26 (1996) $185-191$.

[21] S. Ahmed Ben Hasan, M.M. Dimitrijević, A. Kojović, D.B. Stojanović, K. ObradovićĐuričić, R.M. Jančić-Heinemann, R. Aleksić, The effect of alumina nanofillers size and shape on mechanical behavior of PMMA matrix composite, J. Serb. Chem. Soc. 79 (2014) 1295-1307.

[22] D.B. Stojanović, M. Zrilić, R. Jančić-Heinemann, I. Živković, A. Kojović, P.S. Uskoković, R. Aleksić, Mechanical and anti-stabbing properties of modified thermoplastic polymers impregnated multiaxial p-aramid fabrics, Polym. Adv. Technol. 24 (2013) 772-776. 